\title{
Reducing properties of superalkalis on pyridinic graphene surfaces: a computational study
}

\author{
Fabio Ramondo ${ }^{\mathrm{a}, \mathrm{b}}$, Ilenia Leonzi ${ }^{\mathrm{a}}$, and Giovanni Meloni ${ }^{* a, c}$ \\ aDepartment of Physical and Chemical Sciences, University of \\ L'Aquila, Via Vetoio I-67100, L'Aquila, Italy \\ ${ }^{b}$ Department of Chemistry, University of Rome La Sapienza, \\ P.le A. Moro 5, I-00185, Rome, Italy \\ 'Department of Chemistry, University of San Francisco, San \\ Francisco, CA 94117, USA
}

\begin{abstract}
The hyperlithiated species $\mathrm{Li}_{\mathrm{k}+1} \mathrm{~F}_{\mathrm{k}}(\mathrm{k}=1,2,3$, and 4) have been studied by quantum mechanical (QM) methods. Different structures have been localized for each molecule by the CBS-QB3 composite method: all the isomers show superalkali properties and strong tendency to donate an electron to carbon dioxide forming stable $\mathrm{Li}_{\mathrm{k}+1} \mathrm{~F}_{\mathrm{k}}$. . $\mathrm{CO}_{2}$ complexes. With the aim to find molecular systems able to stabilize superalkalis, geometries of complexes between superalkalis and pyridine and superalkalis and graphene surfaces doped with a pyridinic vacancy were calculated. The pyridinic graphene sheets were modeled with two finite molecular systems $\mathrm{C}_{69} \mathrm{H}_{21} \mathrm{~N}_{3}$ and $\mathrm{C}_{117} \mathrm{H}_{27} \mathrm{~N}_{3}$. The interaction with one pyridine molecule is quite weak and the superalkali maintains its structure and electron properties. The affinity for graphene sheets is instead stronger and the superalkalis tend to deform their geometry to better interact with the graphene surface.
\end{abstract}

*corresponding author; gmeloni@usfca.edu 
However, the superalkalis continue to show the tendency to transfer electrons to carbon dioxide reducing $\mathrm{CO}_{2}$, as found in graphene absence.

\section{Introduction}

The physical and chemical properties of cluster systems often differ from those of the bulk and can depend on the size, geometry, and composition of the cluster [1-4]. A special class of clusters are called "superatoms," which are molecular species that mimic atomic behavior [5-7]. Superatoms of special interest are superalkalis and hyperlithiated compounds that present ionization energies lower than alkalis. These compounds have attracted considerable attention both theoretically and experimentally. In 1978 Kudo et al. [8] and in $1979 \mathrm{Wu}$ at al. [9] observed that gaseous $\mathrm{Li}_{3} \mathrm{O}$ shows an ionization energy $(3.59 \pm 0.2 \mathrm{eV})$ lower than that of solid lithium $(5.36 \pm 0.01$ eV) [10]. Afterwards, also hyperlithiated fluorides produced by laser-ablation source showed superalkali properties [11]. Gutsev and Boldyrev [12,13] proposed the formula $\mathrm{M}_{\mathrm{k}+1} \mathrm{~L}$, where $\mathrm{M}$ is the alkali metal and $\mathrm{L}$ is the electronegative atom with valence $\mathrm{k}$. Applications of superalkalis in many fields of material science have drawn much attention in the past decades. Tendency of hyperlithiated compounds to form clusters with non linear optical properties have been shown by various theoretical studies [14-17]. The electron transfer from superalkalis can be potentially utilized for the conversion of the greenhouse gas $\mathrm{CO}_{2}$ into useful products, such as methanol fuel and carboxylic acid. For example, the superalkali $\mathrm{Li}_{3} \mathrm{~F}_{2}$ [18] can be employed to easily reduce carbon dioxide $\mathrm{CO}_{2}[19]$ and nitrogen $\mathrm{N}_{2}[20]$ with high stability and selectivity. Srivastava has shown that also the smaller $\mathrm{Li}_{2} \mathrm{~F}$ is able to reduce carbon dioxide [21]. Reduction of $\mathrm{CO}_{2}$ can occur also with superalkalis composed by transition metal complexes as well as organic molecules [22]. Srivastava [23] has found that superalkalis can reduce the major air pollutants $\mathrm{NO}_{\mathrm{x}}$ into $\mathrm{NO}_{\mathrm{x}}^{-}$anions. More recently, Meloni et al. [24] showed as $\mathrm{Li}_{3} \mathrm{~F}_{2}$ can be employed to capture volatile organic compounds.

Although hyperlithiated compounds are potentially a new class of catalysts for $\mathrm{CO}_{2}$ activation, the quite extreme conditions necessary to produce them undoubtedly constitute a factor that limits their practical applications. An interesting aspect can be the search of molecular systems able to stabilize the superalkalis without changing their reducing properties. It is well known 
that the adsorption ability of graphene can be significantly strengthened by doping it with heteroatoms [25-27]. For example, the presence of nitrogen on graphene sheets (N-doped graphene) enhances their affinity towards lithium atoms and lithium compounds [28]. To address these issues, we have investigated the interaction between some hyperlithiated compounds and pyridinic nitrogen atoms on graphene sheets. By starting from some complexes between superalkali and pyridine, we studied their structure and stability and how the tendency to coordinate carbon dioxide is modulated by the presence of pyridine. The study was extended to the interaction between superalkalis and graphene sheets by employing two models of graphene with a vacancy consisting of three pyridinic nitrogen atoms. Very recently a theoretical investigation [29] has been carried out on the interactions between alkalis, superalkalis, and nitrogen doped graphene focusing attention on the non linear optical properties of such systems. The aim of the present study is to investigate the superalkalis ability of reducing carbon dioxide in presence and in absence of graphene by considering different structures between graphene, superalkalis, and carbon dioxide. Geometries, energies, and charge distribution were calculated using the CBS-QB3 [30] composite model for smaller systems and Density Functional Theory (DFT) for the systems with graphenic units.

\section{Computational details}

All calculations were performed using Gaussian 09 computational package [31]. Geometries were obtained at the density functional theory (DFT) level employing B3LYP (Becke's three parameter exchange [32] and Lee, Yang, Parr correlation [33] potentials) combined with different basis sets. Structures of $\mathrm{Li}_{\mathrm{k}+1} \mathrm{~F}_{\mathrm{k}}$ species $(\mathrm{k}=1-4), \mathrm{Li}_{\mathrm{k}+1} \mathrm{~F}_{\mathrm{k}}\left(\mathrm{CO}_{2}\right)(\mathrm{k}=1-4)$, and $\mathrm{Li}_{\mathrm{k}+1} \mathrm{~F}_{\mathrm{k}}\left(\mathrm{CO}_{2}\right) \ldots$ pyridine complexes $(\mathrm{k}=2,4)$ were obtained with the $6-311 \mathrm{G}(2 \mathrm{~d}, \mathrm{~d}, \mathrm{p})$ basis set, also widely known as CBSB7, which was developed by Petersson and co-workers [34]. The fully optimized geometries from B3LYP were further computed at the MP2/6-311+G (3d2f,2df,2p) level of theory to refine the electronic energies [35]. The $6-311+\mathrm{G}(3 \mathrm{~d} 2 \mathrm{f}, 2 \mathrm{df}, 2 \mathrm{p})$ basis set is also called CBSB3, and MP2/CBSB3 is the very last step of CBS-QB3 with extrapolation of the total energy [30]. Harmonic vibrational frequencies were also calculated for the $\mathrm{Li}_{\mathrm{k}+1} \mathrm{~F}_{\mathrm{k}}, \mathrm{Li}_{\mathrm{k}+1} \mathrm{~F}_{\mathrm{k}}\left(\mathrm{CO}_{2}\right)(\mathrm{k}=1-4)$, and $\mathrm{Li}_{\mathrm{k}+1} \mathrm{~F}_{\mathrm{k}}\left(\mathrm{CO}_{2}\right) \ldots$ pyridine $(\mathrm{k}=2,4)$ optimized species to assure that they represent at least local minima in the potential energy surface. 
Two polyaromatic hydrocarbons (PAH) were chosen as models to simulate the graphene surface. These highly symmetric $\left(D_{3 h}\right)$ molecules are composed of 28 and 48 benzene rings, including 72 and 121 carbon atoms, respectively. For both PAH's, the pyridinic vacancy was created in the center of the molecule by replacing three carbon with nitrogen atoms and forming the $\mathrm{C}_{69} \mathrm{H}_{21} \mathrm{~N}_{3}$ and $\mathrm{C}_{117} \mathrm{H}_{27} \mathrm{~N}_{3}$ species. Both studied systems have been optimized removing the planarity constraint within $D_{3}$ symmetry. Subsequently, the interaction of the pyridinic vacancy surface with lithium was evaluated in different environments. Firstly, the lithium affinity was estimated by adding a single lithium atom along the $C_{3}$ symmetry axis and by studying the geometry and stability of the relative complexes. Secondly, two superalkalis were considered, $\mathrm{Li}_{3} \mathrm{~F}_{2}$ and $\mathrm{Li}_{5} \mathrm{~F}_{4}$. Each molecule was approached to the pyridinic vacancy of the graphene models and stability and geometries of the relative complexes were evaluated. Lastly, the interaction of superalkali and graphene has been again evaluated in presence of $\mathrm{CO}_{2}$ by considering the molecular complex between graphene, superalkali, and $\mathrm{CO}_{2}$ units.

The CBS-QB3 method employed to analyze smaller clusters is computationally too expensive to yield the energetics of graphene-containing systems. Geometry and energetics of these large models were, therefore, obtained at the B3LYP/6-31G(d) level. The B3LYP method is a reliable and high quality density functional method recently used in the study of graphene and adsorption phenomena [26,36-39], also in conjuction with the 6-31G(d) basis set [40].

The interaction energies, binding energy (BE), of all the molecular complexes were calculated as difference between the energy of the interacting species and the energies of the separated molecules. According to this definition, negative or positive values of BEs correspond to exothermic or endothermic processes, respectively.

The spin densities have been obtained on Mulliken population analysis [41], whereas the ESP method [42] has been utilized to find partial atomic charges. The charge transfer $(\Delta q)$ between the molecular units forming the complex has been estimated using the calculated partial atomic charges. 


\section{Results and discussion}

\section{1 $\mathrm{Li}_{\mathrm{k}+1} \mathrm{~F}_{\mathrm{k}}, \mathrm{CO}_{2}$, and pyridine}

The main purpose of the present study is to show the reduction capability of $\mathrm{Li}_{\mathrm{k}+1} \mathrm{~F}_{\mathrm{k}}$ towards $\mathrm{CO}_{2}$ when the superalkali is bonded to pyridinic nitrogen atoms. In the first section we show the structures of complexes between pyridine and some hyperlithiated species, like $\mathrm{Li}_{3} \mathrm{~F}_{2}$ and $\mathrm{Li}_{5} \mathrm{~F}_{4}$. As reference, we firstly present the optimized structures and relative highest singly occupied molecular orbital (SOMO) of some isolated superalkalis in Figure 1. The planar $C_{2 v}$ symmetry structures of $\mathrm{Li}_{2} \mathrm{~F}$ and $\mathrm{Li}_{3} \mathrm{~F}_{2}$, already determined in a previous computational study [18], are now compared with the larger $\mathrm{Li}_{4} \mathrm{~F}_{3}$ and $\mathrm{Li}_{5} \mathrm{~F}_{4}$ species with the aim to investigate if superalkali properties can be affected by the size of the molecular species. For an easy comparison, all the compounds were initially considered within the $C_{2 v}$ planar symmetry, although $\mathrm{Li}_{3} \mathrm{~F}_{2}, \mathrm{Li}_{4} \mathrm{~F}_{3}$, and $\mathrm{Li}_{5} \mathrm{~F}_{4}$ can be found also with alternative structures. For example, a $C_{s}$ planar structure has been found for $\mathrm{Li}_{3} \mathrm{~F}_{2}$ at only $3 \mathrm{~kJ} / \mathrm{mol}$ above the $C_{2 v}$ isomer [18]. $\mathrm{Li}_{4} \mathrm{~F}_{3}$ has instead various isomers: a second planar isomer (Figure 1) and different non planar structures. The global minimum has $C_{3 v}$ symmetry. The relative stabilities of the planar isomers are $14 \mathrm{~kJ} / \mathrm{mol}\left(C_{s}\right)$ and $23 \mathrm{~kJ} / \mathrm{mol}\left(C_{2 v}\right)$. Preference for a non planar geometry is also found for the larger $\mathrm{Li}_{5} \mathrm{~F}_{4}\left(C_{3 v}\right)$ that shows an isolated $\mathrm{Li}$ tail and a typical cyclic $(\mathrm{LiF})_{\mathrm{n}}$ polymeric structure. An alternative non planar isomer and a $C_{2 v}$ symmetry isomer are $21 \mathrm{~kJ} / \mathrm{mol}$ and $57 \mathrm{~kJ} / \mathrm{mol}$, respectively, higher in energy. All the structures are reproduced in Figure 1. The SOMO's of all the species reported in Figure 1 are very similar with the unpaired electron localized onto the terminal lithium atoms. The calculated AIE's of $3.86 \mathrm{eV}$ for $\mathrm{Li}_{4} \mathrm{~F}_{3}$ and $3.91 \mathrm{eV}$ for $\mathrm{Li}_{5} \mathrm{~F}_{4}$ are lower than the experimental ionization energy of lithium $(5.39 \mathrm{eV})$ and very close to the AIE of $\mathrm{Li}_{3} \mathrm{~F}_{2}(3.80 \mathrm{eV})$ and $\mathrm{Li}_{2} \mathrm{~F}(3.88 \mathrm{eV})$ proving that all these species are superalkalis.

Interaction of superalkalis and pyridine was investigated for two systems of the series, $\mathrm{Li}_{3} \mathrm{~F}_{2}$ and $\mathrm{Li}_{5} \mathrm{~F}_{4}$. Since the equilibrium structure of $\mathrm{Li}_{3} \mathrm{~F}_{2}$ has $C_{2 v}$ symmetry, its interaction with pyridine was evaluated approaching the central Li atom to the nitrogen along the $C_{2}$ symmetry axis and calculating geometries and binding energies. Two structures of $C_{2 v}$ symmetry were proposed: a structure where pyridine and superalkali are coplanar, and a non planar geometry where pyridine is orthogonal to the planar superalkali. A 
<smiles>[O-][O+][O-]</smiles>

(a)

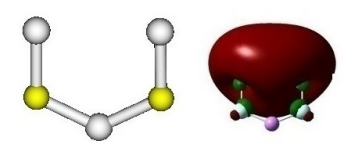

(b)

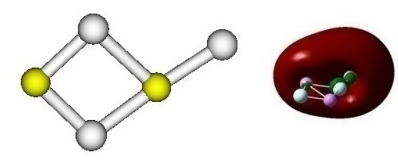

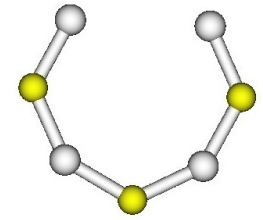
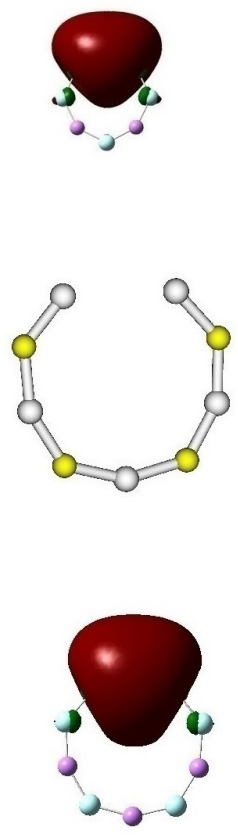

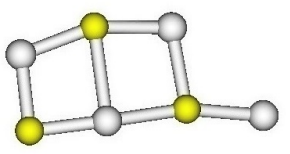

(c)
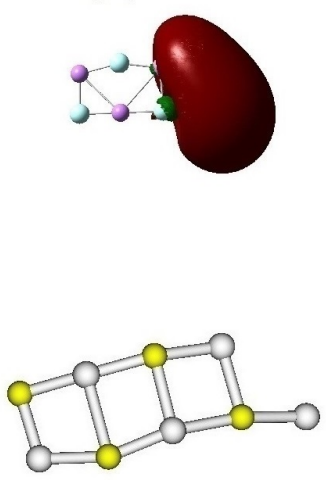

(d)

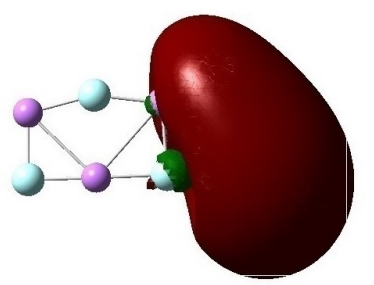

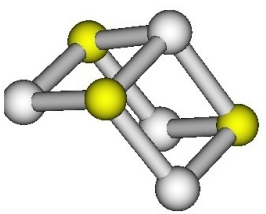
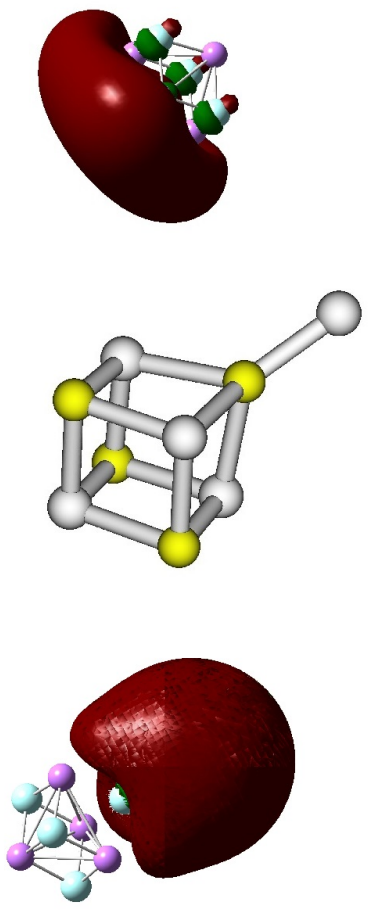

Figure 1: Optimized geometries of $\mathrm{Li}_{2} \mathrm{~F}(\mathrm{a}), \mathrm{Li}_{3} \mathrm{~F}_{2}(\mathrm{~b}), \mathrm{Li}_{4} \mathrm{~F}_{3}(\mathrm{c})$ and $\mathrm{Li}_{5} \mathrm{~F}_{4}(\mathrm{~d})$, and their visualized singly occupied molecular orbitals SOMO's 
third structure, again planar, describes the interaction between the $C_{s}$ isomer of $\mathrm{Li}_{3} \mathrm{~F}_{2}$ and pyridine. The binding energies of the three complexes are indeed very similar and the N...Li intermolecular distances are substantially independent from the structure and orientation of the superlkali. Therefore, Figure 2 a shows only the geometry of the most stable planar $C_{2 v}$ structure. The salient result is that interaction with pyridine is quite weak $(68 \mathrm{~kJ} / \mathrm{mol})$ with intermolecular N...Li distance of $2.037 \AA$ and a modest charge transfer. As a consequence, the molecular properties of each interacting molecule are not expected to drastically change upon complexation. For example, the internal LiF bonds undergo small lengthening, whereas the terminal LiF remains substantially unchanged; the only significant geometrical effect of pyridine interaction is the narrowing of the FLiF bond angle from $129^{\circ}$ to $121^{\circ}$. In the case of the $\mathrm{Li}_{5} \mathrm{~F}_{4}$-pyridine complex, all the three structures of $\mathrm{Li}_{5} \mathrm{~F}_{4}$ were considered and their geometries are reproduced in Figure $2 \mathrm{~b}$. The binding energies of the $C_{2 v}$ isomer is comparable with that of $\mathrm{Li}_{3} \mathrm{~F}_{2}$, whereas the non planar structures show a higher affinity towards pyridine $(83 \mathrm{k} / \mathrm{mol}$ for the $C_{3 v}$ isomer and $91 \mathrm{~kJ} / \mathrm{mol}$ for the other non planar isomer). Another important result emerging from the SOMO's (Figure 2) inspection of all the structures is that the unpaired electron continues to be localized on the hyperlithiated unit and, in particular, on the lithium terminal atoms, like for the isolated species. Before interacting with pyridine these Li atoms of $\mathrm{Li}_{3} \mathrm{~F}_{2}$, for example, carry the extra electron with a spin density of 0.58 each; upon interaction they show a small increase of spin density ( 0.66 each) confirming the strong localization of the extra electron on the terminal Li atoms.

In addition, the removal of an electron from the $\mathrm{Li}_{3} \mathrm{~F}_{2}$-pyridine and $\mathrm{Li}_{5} \mathrm{~F}_{4^{-}}$ pyridine complexes of $C_{2 v}$ symmetry leaves the binding energy of the complexes nearly unchanged $(71 \mathrm{~kJ} / \mathrm{mol})$. This value is calculated by taking the difference between the sum of the energy of the superalkali cation and pyridine and the energy of the complex cation. It is also worth observing that the AIE's of the $\mathrm{Li}_{3} \mathrm{~F}_{2}$-pyridine $(3.76 \mathrm{eV})$ and $\mathrm{Li}_{5} \mathrm{~F}_{4}$-pyridine complexes $(3.88 \mathrm{eV})$ are not far from $3.80 \mathrm{eV}\left(\mathrm{Li}_{3} \mathrm{~F}_{2}\right)$ and $3.91 \mathrm{eV}\left(\mathrm{Li}_{5} \mathrm{~F}_{4}\right)$ of the isolated species proving that the hyperlithiated compounds continues to have superalkali properties upon interaction with pyridine.

Figure 3 shows the interaction structures of $\mathrm{Li}_{\mathrm{k}+1} \mathrm{~F}_{\mathrm{k}}$ with $\mathrm{CO}_{2}$. The previous study [19] revealed that $\mathrm{Li}_{3} \mathrm{~F}_{2}$ has a strong tendency to donate an electron to $\mathrm{CO}_{2}$ taking a bent structure and forming a stable $\mathrm{Li}_{3} \mathrm{~F}_{2} \cdots \mathrm{CO}_{2}$ complex. Similar results are found for the other superalkalis here considered, $\operatorname{Li}_{2} \mathrm{~F}$, $\mathrm{Li}_{4} \mathrm{~F}_{3}$, and $\mathrm{Li}_{5} \mathrm{~F}_{4}$. Each superalkali isomer may interact with carbon dioxide 

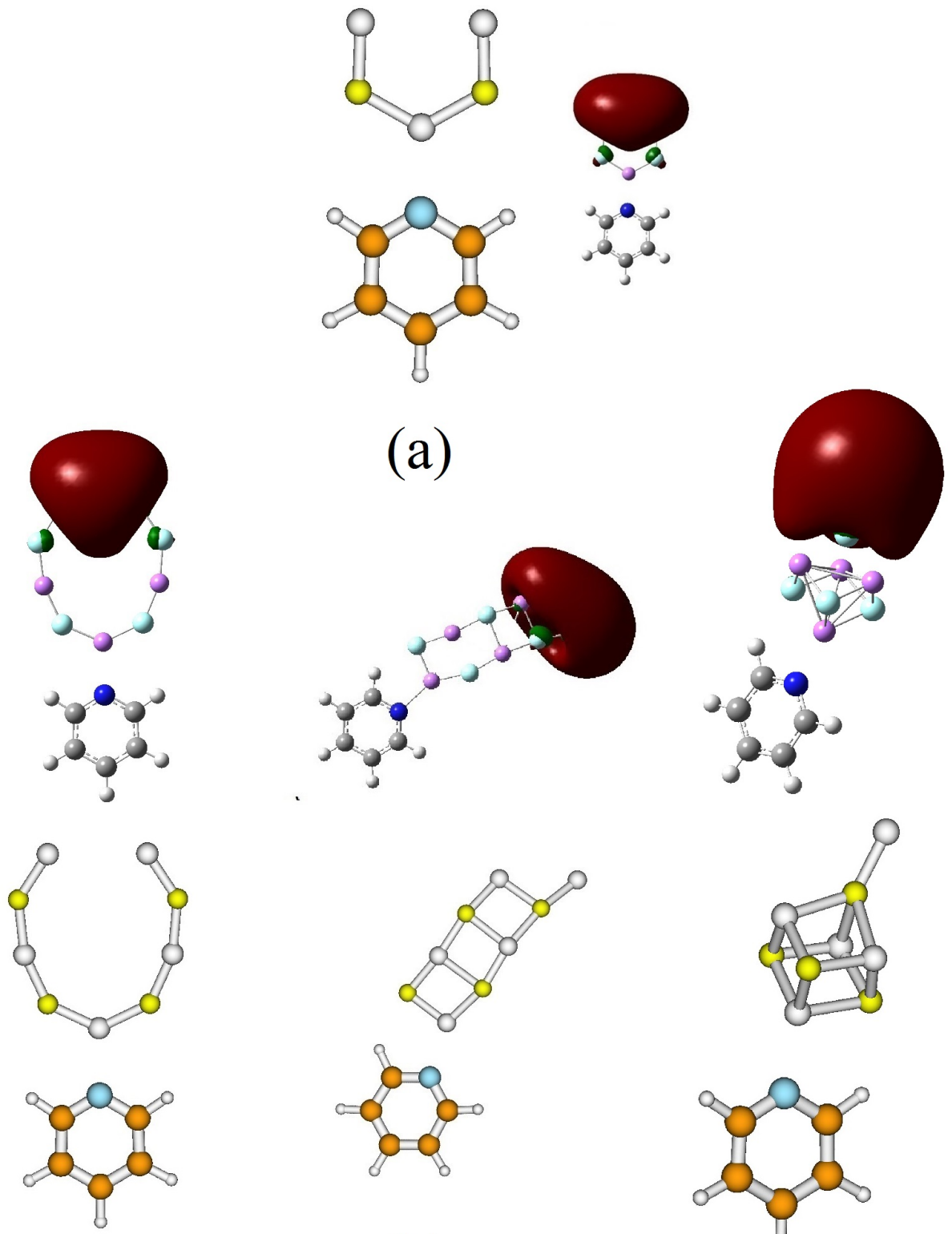

(b)

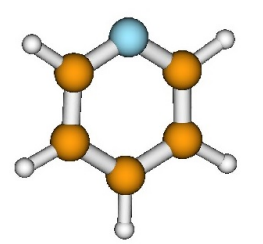

Figure 2: Optimized structures of $\mathrm{Li}_{3} \mathrm{~F}_{2}$-pyridine (a) and $\mathrm{Li}_{5} \mathrm{~F}_{4}$-pyridine (b) complexes and relative visualized SOMO's 
and in all the cases the bent structure assumed by $\mathrm{CO}_{2}$ upon interaction is close to that calculated for the $\mathrm{CO}_{2}$ isolated anion (OCO bond angle = $134^{\circ}$ and $\mathrm{CO}$ bond distance $=1.244 \AA$ ) at the B3LYP/CBSB3 level. As for $\mathrm{Li}_{3} \mathrm{~F}_{2} \cdots \mathrm{CO}_{2}$ [19], two planar cyclic $C_{2 v}$ structures, labeled as (a) and (b) in Figure 3, can be formed with comparable stability. In both the structures each oxygen interacts with a single terminal $\mathrm{Li}$, but the bent $\mathrm{CO}_{2}$ is differently oriented with respect to the superalkali unit. The value of the OCO bond angle is almost constant $\left(134^{\circ}\right)$ in all the cyclic structures labeled as (b) in Figure 3. On the contrary, in the alternative cyclic structures of Figure 3 and labeled as (a), $\mathrm{CO}_{2}$ increases progressively its bending from $142^{\circ}$ in $\mathrm{Li}_{2} \mathrm{~F} \cdots \mathrm{CO}_{2}$ to $134^{\circ}$ in $\mathrm{Li}_{5} \mathrm{~F}_{4} \cdots \mathrm{CO}_{2}$. As for the $\mathrm{Li}_{4} \mathrm{~F}_{3}$ and $\mathrm{Li}_{5} \mathrm{~F}_{4}$ isolated superalkalis, the non planar structures, labelled as (c) in Figure 3, have been found to be the preferred superalkali $\cdots \mathrm{CO}_{2}$ configuration. Once again the global minima are those where the superalkali takes the local $C_{3 v}$ symmetry (see Table 1). It is interesting to note that whereas the relative stabilities of different isomers of each complex seem to depend on the size and structure of the superalkali, the binding energy of the $\mathrm{Li}_{\mathrm{k}+1} \mathrm{~F}_{\mathrm{k}} \cdots \mathrm{CO}_{2}$ systems reveals that the interaction with carbon dioxide does not change drastically with the size of the superalkali (Table 1) with the exception for the $C_{3 v}$ isomer of $\mathrm{Li}_{5} \mathrm{~F}_{4}$. This structure interacts more effectively with $\mathrm{CO}_{2}$ since the excess electron of the superalkali is located on the "anionic cavity" formed by three lithium atoms that, therefore, may interact with carbon dioxide.

The charge transfer, $\Delta q$, has been calculated using the ESP method for all the complexes and the values (Table 1) reveal the ionic character of the interaction with a charge flow from the superalkali to $\mathrm{CO}_{2}$. The amount of charge transfer depends on the size of the superalkali: it decreases from 0.83 $\left(\mathrm{Li}_{2} \mathrm{~F}\right)$ to $0.62\left(\mathrm{Li}_{3} \mathrm{~F}_{2}\right)$, whereas it remains almost unchanged for the symmetric structures of $\mathrm{Li}_{4} \mathrm{~F}_{3}(0.62)$ and $\mathrm{Li}_{5} \mathrm{~F}_{4}$ (0.63). The non planar complexes of $\mathrm{Li}_{4} \mathrm{~F}_{3}$ and $\mathrm{Li}_{5} \mathrm{~F}_{4}$ show a more effective charge transfer, close to that calculated for $\mathrm{Li}_{2} \mathrm{~F}$.

Figure $4 \mathrm{a}$ shows the optimized structure where pyridine, $\mathrm{Li}_{3} \mathrm{~F}_{2}$ and $\mathrm{CO}_{2}$ form a stable complex. By comparing the stabilities of $\mathrm{Li}_{3} \mathrm{~F}_{2}-\mathrm{CO}_{2}, \mathrm{Li}_{3} \mathrm{~F}_{2}$-pyridine and $\mathrm{Li}_{3} \mathrm{~F}_{2}-\mathrm{CO}_{2}$-pyridine we can derive the interaction energy of superalkali with $\mathrm{CO}_{2}$ in presence of pyridine. As reported in Table $1, \mathrm{Li}_{3} \mathrm{~F}_{2}$ has an affinity towards $\mathrm{CO}_{2}$ almost independent of its interaction with pyridine. This agrees with the results discussed above showing that pyridine does not substantially change the properties of the superalkali. Consistently, the intermolecular O...Li distances $(1.822 \AA$ ) are very close to $1.812 \AA$ found for the 


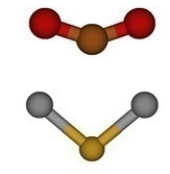

1a

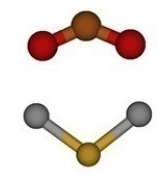

$1 b$

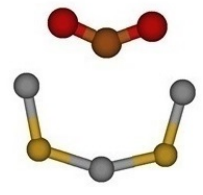

$2 \mathrm{a}$

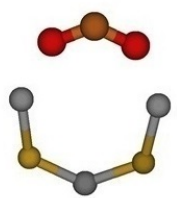

$2 b$

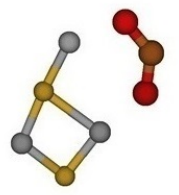

$2 \mathrm{c}$

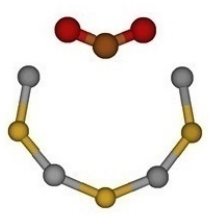

$3 a$

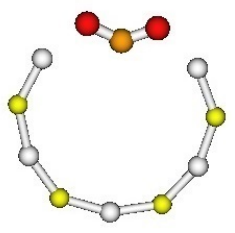

$4 \mathrm{a}$

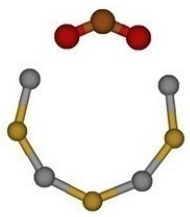

$3 b$

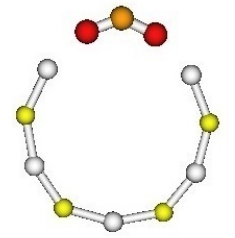

$4 \mathrm{~b}$

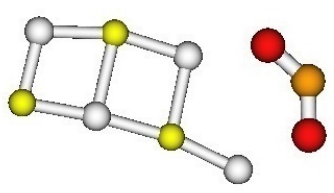

$3 \mathrm{c}$

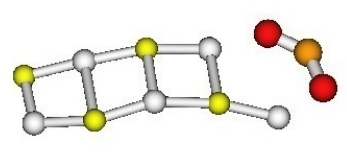

$4 \mathrm{c}$

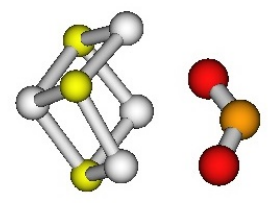

$3 d$

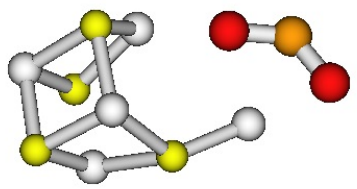

$4 d$

Figure 3: Optimized structures of (1) $\mathrm{Li}_{2} \mathrm{~F} \cdot \mathrm{CO}_{2}$, (2) $\mathrm{Li}_{3} \mathrm{~F}_{2} \cdots \mathrm{CO}_{2}$, (3) $\mathrm{Li}_{4} \mathrm{~F}_{3} \cdots \mathrm{CO}_{2}$ and $(4) \mathrm{Li}_{5} \mathrm{~F}_{4} \cdots \mathrm{CO}_{2}$ complexes 

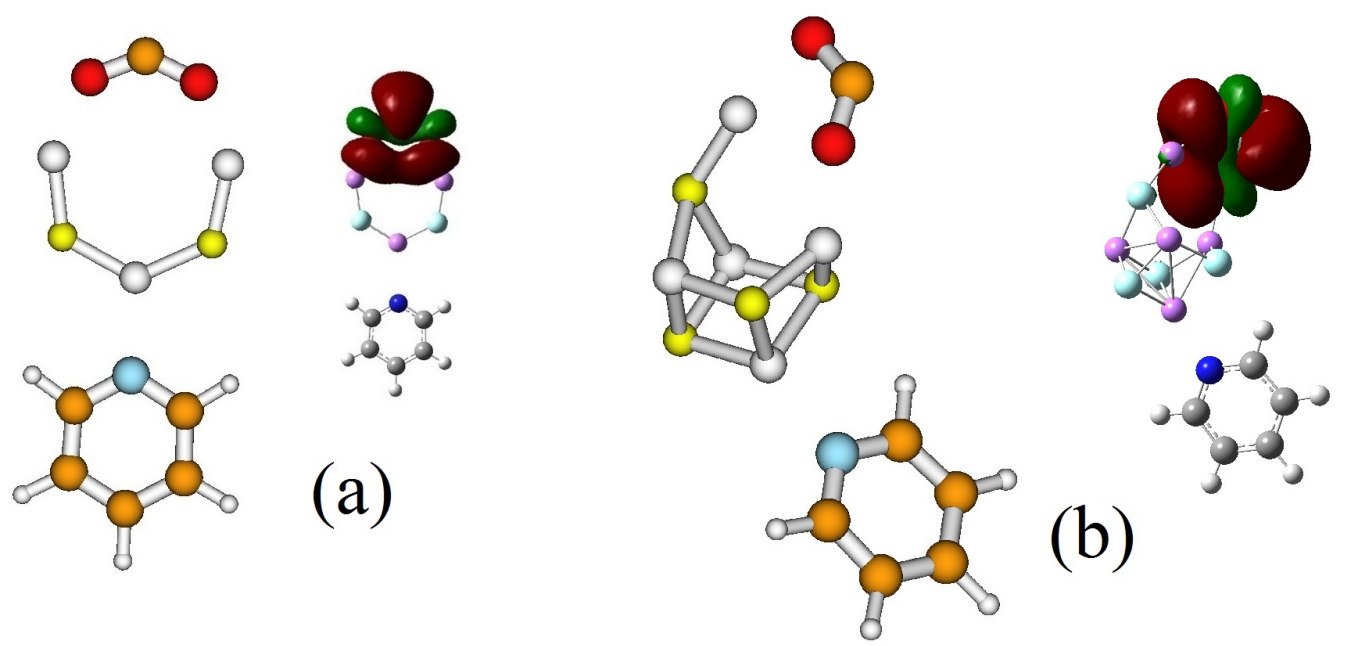

Figure 4: Optimized structures of $\mathrm{Li}_{3} \mathrm{~F}_{2} \cdots \mathrm{CO}_{2} \cdots$ pyridine (a) and $\mathrm{Li}_{5} \mathrm{~F}_{4} \cdots$ - $\mathrm{CO}_{2} \cdots$ pyridine (b) complexes and relative visualized SOMO's

$\mathrm{Li}_{3} \mathrm{~F}_{2}-\mathrm{CO}_{2}$ complex. The bent geometry of carbon dioxide $\left(\mathrm{O}-\mathrm{C}-\mathrm{O}=135^{\circ}\right.$ ), the CO bond distance $(1.24 \AA)$, the features of the SOMO's, and its strong localization on the $\mathrm{CO}_{2}$ portion of the complex, in particular on the carbon atom, indicate that the superalkali easily reduces $\mathrm{CO}_{2}$ also when it interacts with pyridine (Table 1 ). The charge is prevalently localized on $\mathrm{CO}_{2}$ $(-0.74)$ and the charge transfer occurs mainly from superalkali (0.52) and only marginally from pyridine $(0.22)$. As for $\mathrm{Li}_{3} \mathrm{~F}_{2}$, also $\mathrm{Li}_{5} \mathrm{~F}_{4}$ reduces $\mathrm{CO}_{2}$ in presence of pyridine with a comparable charge transfer to $\mathrm{CO}_{2}$. In Figure $4 \mathrm{~b}$ we show the complex between the $\mathrm{Li}_{5} \mathrm{~F}_{4} C_{3 v}$ isomer, pyridine and $\mathrm{CO}_{2}$ : in this case the superalkali and carbon dioxide are bonded by $-158 \mathrm{~kJ} / \mathrm{mol}$, a value again very close to that calculated for the isolated $\mathrm{Li}_{5} \mathrm{~F}_{4} \ldots \mathrm{CO}_{2}$ complex $(-174 \mathrm{~kJ} / \mathrm{mol})$. This suggests that the reducing properties of $\mathrm{Li}_{\mathrm{k}+1} \mathrm{~F}_{\mathrm{k}}$ towards carbon dioxide are not significantly altered by the weak interaction with pyridine.

\section{2 $\quad \mathrm{Li}_{\mathrm{k}+1} \mathrm{~F}_{\mathrm{k}}, \mathrm{CO}_{2}$, and graphene}

Structural features and electronic properties of the graphene-containing systems described in this section were obtained at the B3LYP/6-31G(d) level of 

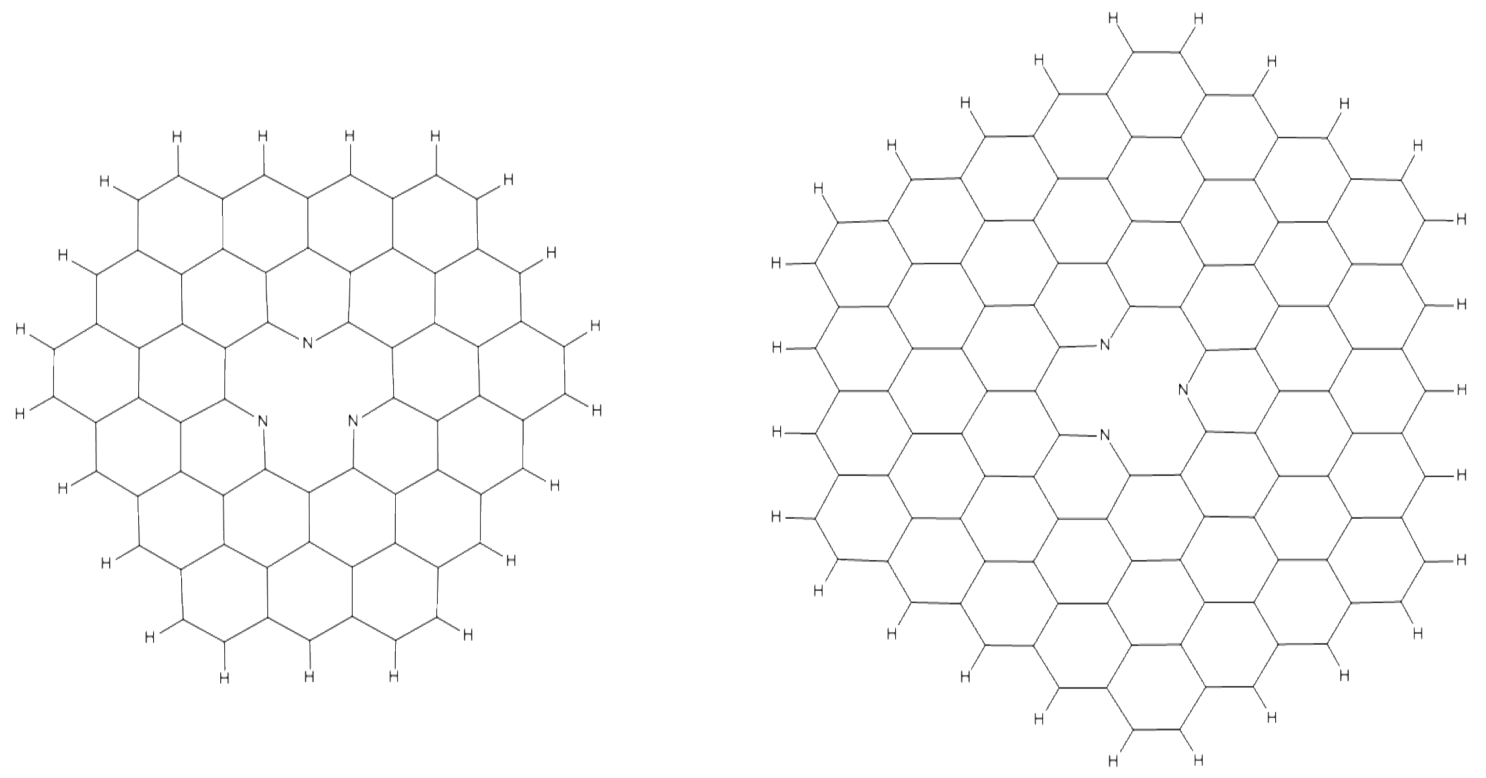

Figure 5: $\mathrm{C}_{69} \mathrm{H}_{21} \mathrm{~N}_{3}$ and $\mathrm{C}_{117} \mathrm{H}_{27} \mathrm{~N}_{3}$ molecules used as 3N-graphene model.

theory. The choice of the B3LYP method for these large molecular systems has been driven by some considerations. Firstly, this DFT functional has already been successfully applied in the study of adsorption phenomena on graphene surfaces $[26,36-39]$. Secondly, the CBS-QB3 results obtained for superalkalis and their complexes with $\mathrm{CO}_{2}$ and pyridine are not drastically far from those obtained at the B3LYP/6-31G(d) level, (see Table 1) with differences in binding energies no higher than $30 \mathrm{~kJ} / \mathrm{mol}$.

$\mathrm{C}_{69} \mathrm{H}_{21} \mathrm{~N}_{3}$ and $\mathrm{C}_{117} \mathrm{H}_{27} \mathrm{~N}_{3}$ composed by 28 and 48 aromatic rings (Figure 5), respectively, are our models used as finite-size pyridinic graphene sheets. Both the systems show a pyridinic vacancy by three nitrogen atoms localized at the center. Their geometries were optimized within the $D_{3 h}$ symmetry.

Interaction between $3 \mathrm{~N}$-graphene and lithium has been investigated approaching a lithium atom along the $C_{3}$ axis and optimizing the geometry of the complex. The lithium atom is pulled above the graphene plane and, moreover, the graphene structure is slightly distorted from planarity in the region of the interaction. The strong affinity for lithium is well witnessed by the large binding energy $(-400 \mathrm{~kJ} / \mathrm{mol})$ for both the molecular systems. It means that lithium is strictly connected to three pyridinic nitrogen through quite short Li...N bond distances $(1.833 \AA)$. The structural distortions of 

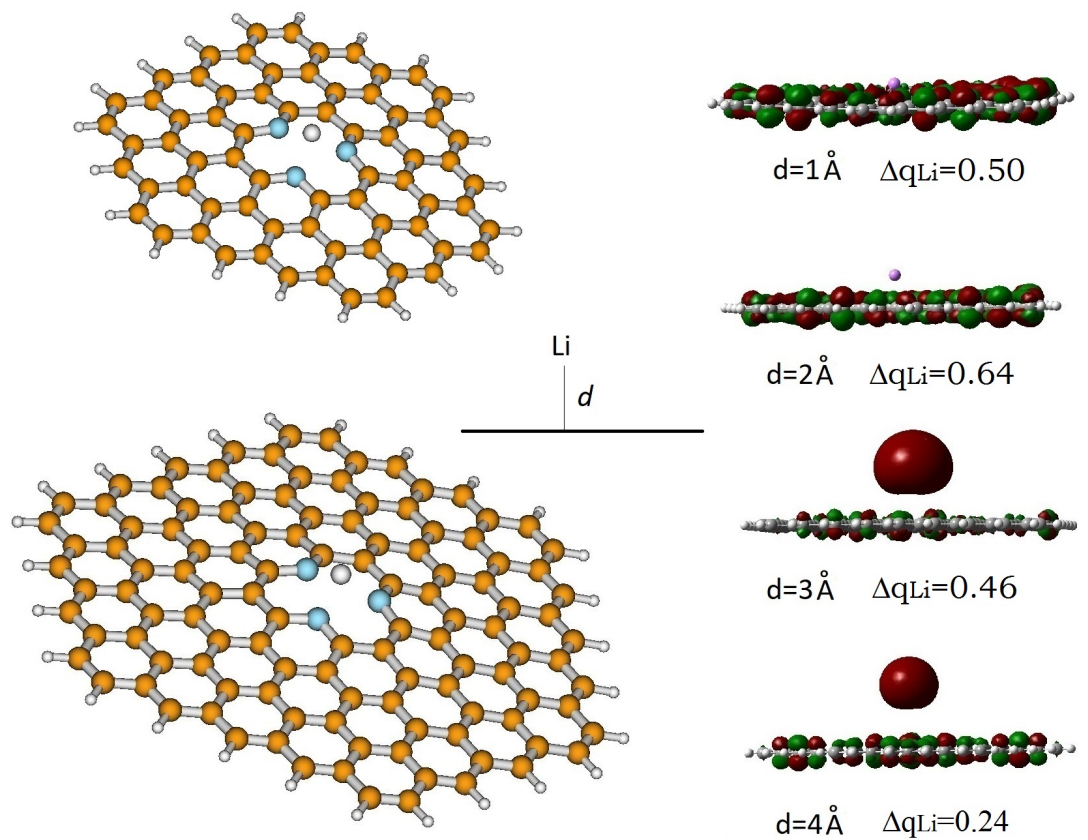

$\mathrm{d}=2 \AA \quad \Delta \mathrm{qLi}=0.64$

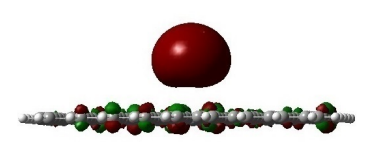

$\mathrm{d}=3 \AA \quad \Delta \mathrm{qLi}=0.46$

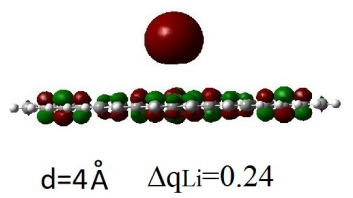

Figure 6: Optimized geometries of $\mathrm{C}_{69} \mathrm{H}_{21} \mathrm{~N}_{3}$ and $\mathrm{C}_{117} \mathrm{H}_{27} \mathrm{~N}_{3}$ interacting with a lithium atom. SOMO of the $\mathrm{C}_{117} \mathrm{H}_{27} \mathrm{~N}_{3}$...Li complex visualized at different distances (d) between lithium and graphene plane and charge transfer $\Delta q$ (a.u.) from lithium to graphene. 


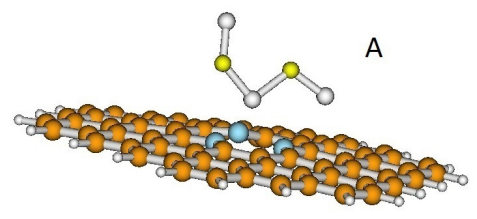

B

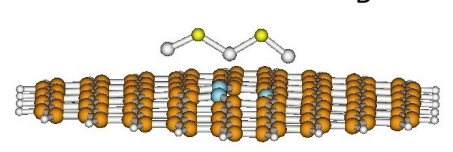

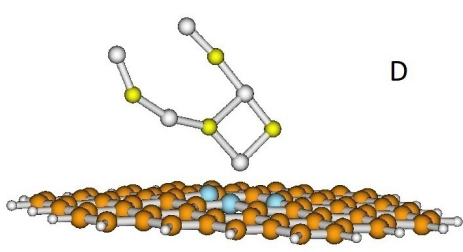
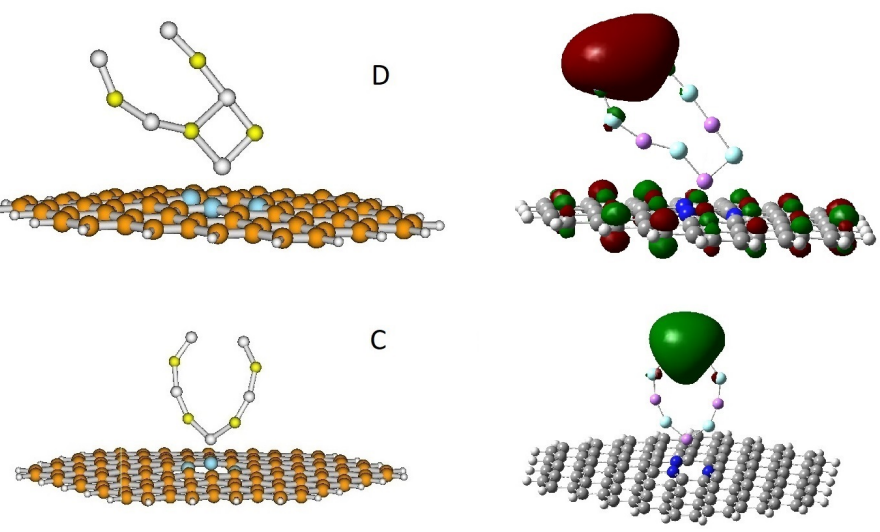

Figure 7: Optimized geometries of $\mathrm{C}_{69} \mathrm{H}_{21} \mathrm{~N}_{3}$ interacting with $\mathrm{Li}_{3} \mathrm{~F}_{2}$ (A) and $\mathrm{Li}_{5} \mathrm{~F}_{4}(\mathrm{D})$ and $\mathrm{C}_{117} \mathrm{H}_{27} \mathrm{~N}_{3}$ interacting with $\mathrm{Li}_{3} \mathrm{~F}_{2}(\mathrm{~B})$ and $\mathrm{Li}_{5} \mathrm{~F}_{4}(\mathrm{C})$ and SOMO's of the relative complexes.

the graphene system are limited to the pyridinic rings: lithium coordination causes an increase of the $\mathrm{CN}$ bond distance, from $1.332 \AA$ to $1.349 \AA$, and the $\mathrm{CNC}$ ring bond angles, from $122.3^{\circ}$ to $123.8^{\circ}$. The ionic component of the lithium graphene interaction is clearly suggested by the significant charge transfer, $\Delta q$, from lithium to graphene (0.54). Figure 6 shows the SOMO for the $\mathrm{C}_{117} \mathrm{H}_{27} \mathrm{~N}_{3}$...Li complex visualized at different distances between lithium and graphene plane. The unpaired electron is mainly localized on graphene when lithium is bonded to the surface $(2 \AA)$, whereas the contribution on lithium arises when atom is progressively removed from the surface (from 3 $\AA$ upwards).

The determination of graphene and superalkalis structures is certainly a complex problem since the number of local minima of the potential energy surface is quite large and a systematic search is outside our computational capabilities. Therefore, we considered this interaction through a limited number of models: $\mathrm{Li}_{3} \mathrm{~F}_{2}$ and $\mathrm{Li}_{5} \mathrm{~F}_{4}$ were positioned above the graphene plane with a local and initial $C_{2 v}$ symmetry structure and by orienting the superalkali perpendicularly to the graphene sheet with the central lithium atom approaching the center of the graphene surface, which is towards the pyridinic vacancy. Both the $\mathrm{C}_{69} \mathrm{H}_{21} \mathrm{~N}_{3}$ and $\mathrm{C}_{117} \mathrm{H}_{27} \mathrm{~N}_{3}$ systems were considered and the geometries of their complexes with superalkalis were fully optimized without any symmetry constraint. For some complexes different isomers were local- 

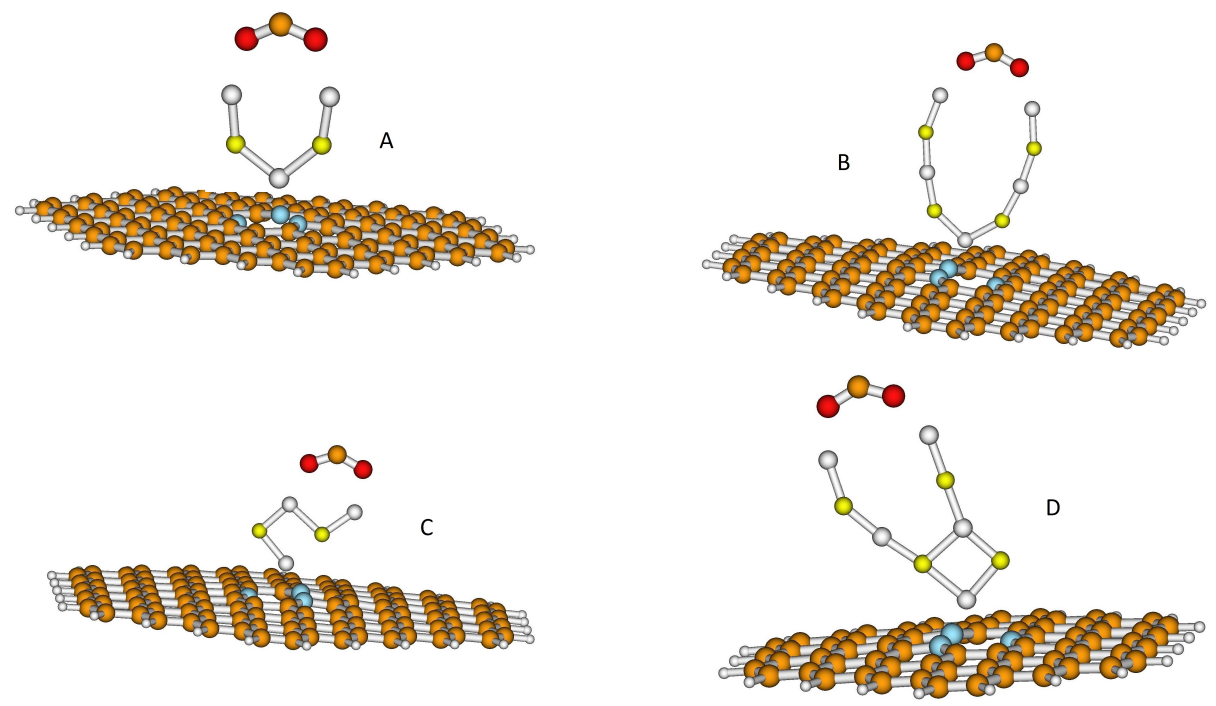

Figure 8: Some optimized structures of graphene $\cdots \mathrm{Li}_{3} \mathrm{~F}_{2} \cdots \mathrm{CO}_{2}(\mathrm{~A}, \mathrm{C})$ and graphene $\cdots \mathrm{Li}_{5} \mathrm{~F}_{4} \cdots \mathrm{CO}_{2}$ complexes $(\mathrm{B}, \mathrm{D})$.

ized and relative stabilities are reported in Table 2. In all the cases the central lithium tends to interact with three nitrogen atoms, as found in the case of Li-doped graphene previously discussed, although the Li...N distances are longer (ranging from $2.11 \AA$ to $2.35 \AA$ ). In the case of $\mathrm{Li}_{3} \mathrm{~F}_{2}$ and $\mathrm{C}_{69} \mathrm{H}_{21} \mathrm{~N}_{3}$, the marked affinity of graphene for lithium implies that the superalkali changes its structure by orienting the remaining lithium atoms towards the graphene plane to favour such interactions. Consequently, the initial $C_{2 v}$ symmetry structure of $\mathrm{Li}_{3} \mathrm{~F}_{2}$ is deformed to allow further lithium-graphene interactions involving the second (Figure 7A) and the third lithium atom (Figure 7B). It means that in presence of graphene some less stable isomers of $\mathrm{Li}_{3} \mathrm{~F}_{2}$, as the $\mathrm{C}_{s}$ symmetry one (Figure 1 ), are now preferred to the $C_{2 v}$ isomer. In particular, the bent $\mathrm{W}$ arrangement assumed by $\mathrm{Li}_{3} \mathrm{~F}_{2}$ on the graphene surface (Figure 7B), found as the most favorable structure, can be thought as derived from an alternative isomer, having a quasi linear structure, that for the isolated $\mathrm{Li}_{3} \mathrm{~F}_{2}$ was found $71 \mathrm{~kJ} / \mathrm{mol}$ higher in energy. Binding energies of such complexes, calculated as difference between the energy of the complex and those of graphene and $\mathrm{Li}_{3} \mathrm{~F}_{2}\left(C_{2 v}\right)$, indicate that the superalkali strongly adsorbs on graphene. Interaction is stronger for the $\mathrm{W}$ isomer $(-311$ 
$\mathrm{kJ} / \mathrm{mol})$ than for the $\mathrm{A}$ isomer $(-276 \mathrm{~kJ} / \mathrm{mol})$ because the geometry of the $\mathrm{W}$ isomer allows the simultaneous interaction of three lithium atoms with graphene: the central lithium with three nitrogens and the terminal atoms with the graphene surface. For the larger graphene model, $\left(\mathrm{C}_{117} \mathrm{H}_{27} \mathrm{~N}_{3}\right)$ we considered only the most favorable $\mathrm{W}$ structure of $\mathrm{Li}_{3} \mathrm{~F}_{2}$ : its binding energy $(-266 \mathrm{~kJ} / \mathrm{mol})$ is slightly smaller than that of $\mathrm{Li}_{3} \mathrm{~F}_{2} \ldots \mathrm{C}_{69} \mathrm{H}_{21} \mathrm{~N}_{3}$.

The situation changes for $\mathrm{Li}_{5} \mathrm{~F}_{4}$. Herein the superalkali, after interaction with graphene, may preserve the orientation upward of the terminal lithium atoms (Figure 7C), as found for the isolated molecule. This structural arrangement shows a smaller affinity towards graphene: binding energy is -97 $\mathrm{kJ} / \mathrm{mol}$ when the surface is modeled by $\mathrm{C}_{69} \mathrm{H}_{21} \mathrm{~N}_{3}$ and $-85 \mathrm{k} / \mathrm{mol}$ when the surface is described by $\mathrm{C}_{117} \mathrm{H}_{27} \mathrm{~N}_{3}$. For the $\mathrm{C}_{69} \mathrm{H}_{21} \mathrm{~N}_{3}$ model system, additional structures were found where $\mathrm{Li}_{5} \mathrm{~F}_{4}$ assumes orientations able to improve the interactions with graphene surface as witnessed by the structure reproduced in Figure 7D. Also in this case, the interaction with graphene is weaker $(-121$ $\mathrm{kJ} / \mathrm{mol}$ ) than that found for $\mathrm{Li}_{3} \mathrm{~F}_{2}$. The weaker affinity of $\mathrm{Li}_{5} \mathrm{~F}_{4}$ could depend on the structure of the superalkali that tends to take non planar geometries. However, we started optimizations from the planar structure of $\mathrm{Li}_{5} \mathrm{~F}_{4}$ to have a homogeneous comparison with the planar $\mathrm{Li}_{3} \mathrm{~F}_{2}$.

The visualization of the SOMO's of the $\mathrm{Li}_{5} \mathrm{~F}_{4}$-graphene structures (Figure 7) indicates that the unpaired electron continues to be localized on the terminal lithium atoms and only marginally on the graphene unit. This electronic distribution suggests that the electron properties of the hyperlithiated species seem to be not strongly altered by the graphene adsorption. From these results, it is worthwhile to notice that the binding energy of the superalkalis with pyridine is much weaker than that of the superalkalis with pyridinic graphene because in the larger systems more Li atoms can interacts with more $\mathrm{N}$ atoms, therefore, stabilizing the complex.

Lastly, we considered the interaction of superalkalis with carbon dioxide in presence of pyridinic graphene by approaching $\mathrm{CO}_{2}$ to $\mathrm{Li}_{3} \mathrm{~F}_{2}$ and $\mathrm{Li}_{5} \mathrm{~F}_{4}$, initially oriented with the terminal lithium atoms upward in order to favor interaction with $\mathrm{CO}_{2}$. For such three-molecular systems we found a complex (Figures 8A and 8B), where the superalkali and $\mathrm{CO}_{2}$ form the same cyclic structure already observed in absence of graphene. This structure was localized on both the $\mathrm{C}_{69} \mathrm{H}_{21} \mathrm{~N}_{3}$ and $\mathrm{C}_{117} \mathrm{H}_{27} \mathrm{~N}_{3}$ surfaces. As for the pyridine case, we evaluated the interaction energy between superalkali and $\mathrm{CO}_{2}$ on graphene by comparing stabilities of the superalkali-graphene- $\mathrm{CO}_{2}$ and superalkaligraphene systems. Similarly, we can evaluate the binding energy of graphene 
and superalkali in presence of $\mathrm{CO}_{2}$ as difference between the energy of the system $\mathrm{CO}_{2} \cdots$ superalkali $\cdots$ graphene and those of $\mathrm{CO}_{2} \cdots$ superalkali and graphene. The results reported in Table 2 indicate that graphene may affect the binding energy of the superalkali- $\mathrm{CO}_{2}$ complex. In particular, the coordination with carbon dioxide is weakened when the superalkali species strongly interacts with graphene, as for $\mathrm{Li}_{3} \mathrm{~F}_{2}$. The $C_{2 v}$ symmetry isomer of $\mathrm{Li}_{3} \mathrm{~F}_{2}$ is bonded to $\mathrm{CO}_{2}$ by $-118 \mathrm{~kJ} / \mathrm{mol}$ on $\mathrm{C}_{69} \mathrm{H}_{21} \mathrm{~N}_{3}$ and by $-147 \mathrm{~kJ} / \mathrm{mol}$ on $\mathrm{C}_{117} \mathrm{H}_{27} \mathrm{~N}_{3}$, whereas the binding energy of the $\mathrm{Li}_{3} \mathrm{~F}_{2}-\mathrm{CO}_{2}$ complex is -180 $\mathrm{kJ} / \mathrm{mol}$ in absence of graphene at the same level of calculation, B3LYP/6$31 \mathrm{G}(\mathrm{d})$. In this case, charge transfer to $\mathrm{CO}_{2}$ involve both the superalkali species (0.36) and graphene (0.21). Consistently, the binding energy between $\mathrm{Li}_{3} \mathrm{~F}_{2}$ and graphene weakens in presence of $\mathrm{CO}_{2}$ (see Table 2). On the contrary, when the superalkali is not so strongly bonded to the graphene surface, as for $\mathrm{Li}_{5} \mathrm{~F}_{4}$, its energy interaction with carbon dioxide is nearly unchanged $\left(-169 \mathrm{~kJ} / \mathrm{mol}\right.$ on $\mathrm{C}_{69} \mathrm{H}_{21} \mathrm{~N}_{3}$ and $-175 \mathrm{~kJ} / \mathrm{mol}$ on $\left.\mathrm{C}_{117} \mathrm{H}_{27} \mathrm{~N}_{3}\right)$ with respect to the value calculated in graphene absence, $-179 \mathrm{~kJ} / \mathrm{mol}$. Similarly, the presence of $\mathrm{CO}_{2}$ does not significantly affect the binding energy between $\mathrm{Li}_{5} \mathrm{~F}_{4}$ and graphene. In this case, the charge analysis indicates that the charge flux towards $\mathrm{CO}_{2}$ comes mainly from the superalkali $(+0.7)$ and only marginally from graphene $(+0.1)$. The SOMO's analysis of these complexes shows again a strong localization of the unpaired electron on the $\mathrm{CO}_{2}$ unit along with a smaller contribution from graphene carbon atoms.

The competition between graphene surface and carbon dioxide towards lithium atoms of the superalkali can lead to the formation of further structures reproduced in Figure 8. $\mathrm{Li}_{3} \mathrm{~F}_{2}$ and $\mathrm{Li}_{5} \mathrm{~F}_{4}$ may orient their $\mathrm{LiF}$ groups in order to simultaneously coordinate graphene and carbon dioxide, as occurs in Figures $8 \mathrm{C}$ and $8 \mathrm{D}$. These structures are quite similar to those determined for the isolated superalkali... $\mathrm{CO}_{2}$ complexes with Li...O distances not far from the values optimized for the complexes in graphene absence. As observed in graphene absence, again, the complexes containing asymmetric structures of $\mathrm{Li}_{3} \mathrm{~F}_{2}$ and $\mathrm{Li}_{5} \mathrm{~F}_{4}$ represent lower energy geometries. In addition, the geometry of the carbon dioxide as well as the charge flux towards $\mathrm{CO}_{2}$ indicates that reduction of carbon dioxide occurs also in these alternative structures. However, the high number of geometrical degrees of freedom of these systems gives a high structural flexibility to the superlkalis $\cdots \mathrm{CO}_{2}$ complexes on pyridinic graphene and we cannot exclude that alternative non planar geometries can be formed on graphene substrates. 


\section{Conclusions}

Reduction capability of the hyperlithiated species $\mathrm{Li}_{\mathrm{k}+1} \mathrm{~F}_{\mathrm{k}}(\mathrm{k}=1,2,3$, and 4) towards carbon dioxide has been evaluated by quantum mechanical methods. The isolated hyperlithiated species are superalkali compounds with AIE lower than lithium. Except for $\mathrm{Li}_{2} \mathrm{~F}$, different structures have been localized: $C_{2 v}, C_{s}$, and non planar isomers. Preference for non planar geometries have been found for $\mathrm{Li}_{4} \mathrm{~F}_{3}$ and $\mathrm{Li}_{5} \mathrm{~F}_{4}$ with equilibrium structures of $C_{3 v}$ symmetry. The SOMO of each structure shows that the unpaired electron is localized on the terminal lithium atoms and can be transferred to carbon dioxide to form stable $\mathrm{Li}_{\mathrm{k}+1} \mathrm{~F}_{\mathrm{k}} \ldots \mathrm{CO}_{2}$ complexes. The bent geometry of $\mathrm{CO}_{2}$, the $\mathrm{CO}$ bond distances, and the SOMO's features of the complexes indicate that all the superalkalis of different sizes easily reduce carbon dioxide. Such reducing properties have been then evaluated proposing some molecular systems able to stabilize the superkalis. The affinity of lithium towards pyridinic nitrogen atoms has been considered by investigating firstly the interaction with pyridine. $\mathrm{Li}_{3} \mathrm{~F}_{2}$ and $\mathrm{Li}_{5} \mathrm{~F}_{4}$ can interact quite weakly with one molecule of pyridine forming a molecular complex with a modest charge transfer, maintaining their superalkali properties and continuing to reduce carbon dioxide as occurs in pyridine absence. Electron properties of $\mathrm{Li}_{3} \mathrm{~F}_{2}$ and $\mathrm{Li}_{5} \mathrm{~F}_{4}$ have been then considered in presence of graphene sheets doped with pyridinic vacancy by modeling the graphene surface with two molecular systems $\mathrm{C}_{69} \mathrm{H}_{21} \mathrm{~N}_{3}$ and $\mathrm{C}_{117} \mathrm{H}_{27} \mathrm{~N}_{3}$. The presence of a pyridinic vacancy by three nitrogen atoms localized at the centre of the sheet allows strong interactions between lithium atoms of the superalkalis and graphene surface. The marked affinity of pyridinic graphene for lithium implies that the superlkali can change the initial $C_{2 v}$ structure by orienting the terminal lithium atoms towards the graphene surface. This tendency depends on the size of the superalkali: while $\mathrm{Li}_{5} \mathrm{~F}_{4}$ may preserve initial upward orientations of the $\mathrm{LiF}$ bonds, $\mathrm{Li}_{3} \mathrm{~F}_{2}$ deform quite easily its initial geometry. When the graphene surface and carbon dioxide are simultaneously considered, we found structures where the superalkali coordinates both the molecular units. Both $\mathrm{Li}_{3} \mathrm{~F}_{2}$ and $\mathrm{Li}_{5} \mathrm{~F}_{4}$, upon interaction with graphene, can still reduce carbon dioxide forming cyclic structures as found for the isolated species. Reduction of carbon dioxide may occur for all the structures with lithium terminal atoms, both symmetric, as the initial $C_{2 v}$ isomer, and asymmetric. As a general trend we can conclude that there is a competition between graphene and $\mathrm{CO}_{2}$ towards the superalkali. On the basis of our results, we observe that $\mathrm{Li}_{3} \mathrm{~F}_{2}$ shows a higher affinity for 
graphene than $\mathrm{Li}_{5} \mathrm{~F}_{4}$ whereas, on the contrary, a smaller affinity for $\mathrm{CO}_{2}$ than $\mathrm{Li}_{5} \mathrm{~F}_{4}$. Within the limits of our molecular models, our calculations indicates, therefore, that pyridinic sites on graphene surfaces can significantly adsorb

hyperlithiated species without changing their reducing ability towards carbon dioxide.

\section{Acknowledgment}

GM would like to acknowledge the funding from the ACS-PRF under the grant $\sharp 56067$-UR6.

Keywords: pyridinic graphene, reduction of $\mathrm{CO}_{2}$, superalkali, structure, DFT

\section{References}

[1] S. N. Khanna, P. Jena, Phys. Rev. B 1995, 51, 13705-13716

[2] S. A. Claridge, A. W. Castleman Jr., S. N. Khanna, C. B. Murray, A. Sen, P. S. Weiss, ACS Nano 2009, 3, 244-255

[3] M. Qian, A. C. Reber, A. Ugrinov, N. K. Chaki, S. Mandal, H. M. Saavedra, S. N. Khanna, A. Sen, P. S. Weiss, ACS Nano 2010, 4, 235240

[4] A. W. Castleman Jr. J. Phys. Chem. Lett. 2011, 2, 1062-1069

[5] P. Jena and A. W. Castleman, Jr. (eds.) A. C. Reber, S. N. Khanna, A. W. Castleman Jr., Nanoclusters - A Bridge Across Discipline, Superatoms: From Motifs to Materials Elsevier 2010,

[6] Z. Luo , A. W. Castleman Jr., Acc. Chem. Res., 2014,47, 2931-2940, 2014.

[7] A. M. Champsaur, A. Velian, D. W. Paley, B. Choi, X. Roy, M. L. Steigerwald, C. Nuckolls, Nano Lett. 2016, 16, 5273-5277

[8] H. Kudo, C. H. Wu, H. R. Ihle, J. Nucl. Mater. 1978, 78, 380-389 
[9] C. H. Wu, H. Kudo, H. R. Ihle, J. Chem. Phys. 1979, 70, 1815-1820

[10] P. Dugourd, D. Rayane, P. Labastie, B. Vezin, J. Chevaleyre, M. Broyer, Chem. Phys. Lett. 1992, 197, 433-437

[11] K. Yokoyama, N. Haketa, H. Tanaka, K. Furukawa, H. Kudo, Chem. Phys. Letters 2000, 330, 339-346

[12] G. L. Gutsev, A. I. Boldyrev, Chem. Phys. 1981, 56, 277-283

[13] G. L. Gutsev, A. I. Boldyrev, Chem. Phys. Lett. 1982, 92, 262-266

[14] A. K. Srivastava, N. Misra Mol. Simul. 2016, 42, 981-985

[15] A. K. Srivastava, N. Misra Chem. Phys. Lett. 2015, 39, 307-309

[16] A. K. Srivastava, N. Misra J. Mol. Model. 2015, 21, 305-310

[17] A. K. Srivastava, N. Misra New J. Chem. 2016, 40, 5467-5472

[18] E. Cochran, G. Meloni, J. Chem. Phys. 2014, 140, 204319-204331

[19] H. Park, G. Meloni, Dalton Trans. 2017, 46, 11942-11949

[20] H. Park, G. Meloni, ChemPhysChem 2018, 19, 256-260

[21] A. K. Srivastava Int. J. Quantum. Chem. 2018, 118, e25598

[22] T. Zhao, Q. Wang, P. Jena Nanoscale 2017, 9, 4891-4897

[23] A. K. Srivastava, Chem. Phys. Lett. 2018, 695, 205-210

[24] H. Park, G. Meloni, ChemPhysChem 2018, 19, 2266-2271

[25] M. Zhou, Y. H. Lu, Y. Q. Cai, C. Zhang, Y. P. Feng, Nanotechnology 2011, 385502

[26] D. Duzenli, J. Phys. Chem. C 2016, 120, 20149-20157

[27] S. Liu, S. Huang, Carbon 2017, 115, 11-17

[28] L. G. Bulusheva, M. A. Kanygin, V. E. Arkhipov, K. M. Popov, Yu. V. Fedoseeva, D. A. Smirnov, A. V. Okotrub, J. Phys. Chem. C 2017, $121,5108-5114$ 
[29] Y. D. Song, L. Wang, Q. T. Wang, Optik 2018, 154, 411-420

[30] B. Sirjean, R. Fournet, P. Glaude, M. F. Ruiz-Lopez, Chem. Phys. Lett. 2007, 435, 152-156

[31] M. J. Frisch, G. W. Trucks, H. B. Schlegel, G. E. Scuseria, M. A. Robb, J. R. Cheeseman, G. Scalmani, V. Barone, B. Mennucci, G. A. Petersson, H. Nakatsuji, M. Caricato, X. Li, H. P. Hratchian, A. F. Izmaylov, J. Bloino, G. Zheng, J. L. Sonnenberg, M. Hada, M. Ehara, K. Toyota, R. Fukuda, J. Hasegawa, M. Ishida, T. Nakajima, Y. Honda, O. Kitao, H. Nakai, T. Vreven, J. A. Montgomery, Jr., J. E. Peralta, F. Ogliaro, M. Bearpark, J. J. Heyd, E. Brothers, K. N. Kudin, V. N. Staroverov, R. Kobayashi, J. Normand, K. Raghavachari, A. Rendell, J. C. Burant, S. S. Iyengar, J. Tomasi, M. Cossi, N. Rega, J. M. Millam, M. Klene, J. E. Knox, J. B. Cross, V. Bakken, C. Adamo, J. Jaramillo, R. Gomperts, R. E. Stratmann, O. Yazyev, A. J. Austin, R. Cammi, C. Pomelli, J. W. Ochterski, R. L. Martin, K. Morokuma, V. G. Zakrzewski, G. A. Voth, P. Salvador, J. J. Dannenberg, S. Dapprich, A. D. Daniels, . Farkas, J. B. Foresman, J. V. Ortiz, J. Cioslowski, and D. J. Fox. Gaussian 09 Revision D.01. Gaussian Inc., Wallingford CT, 2009.

[32] A. D. Becke, J. Chem. Phys. 1993, 98, 5648-5652

[33] C. Lee, W. Yang, R. Parr, Phys. Rev. B 1988, 37, 785-789

[34] J. A. Montgomery, M. J. Frisch, J. W. Ochterski, G. A. Petersson, J. Chem. Phys. 2000, 112, 6532-6542

[35] B. Balta, G. Monard, M. F. Ruiz-Ljpez, M. Antoine, A. Grand, S. Boschi-Muller, G. Branlant, J. Phys. Chem. A 2006, 110, 7628-7636

[36] Z. Maaghoul, F. Fazileh, J. Kakemam, Phys. E Low-Dimens. Syst. Nanostruct. 2015, 66, 176-180

[37] A. S. Rad, Appl. Surf. Sci. J. 2015, 357, 1217-1224

[38] B. Wanno, C. Tabtimsai, Superlattices Microstruct. 2014, 67, 110-117

[39] C. Zhu, G. Yang, ChemPhysChem 2016, 17, 2482-2488

[40] M. Malcek, M. N. D. S. Cordeiro Physica E 2018, 95, 59-70 
[41] F. Martin, H. Zipse, J. Comput. Chem. 2005, 26, 97-105

[42] C. Chipot, B. Maigret, J. L. Rivail, H. A. Scheraga, J. Phys. Chem. A 1992, 96, 10276-10284 
Table 1: Relative stability, $\Delta E$, between isomers and binding energy, $B E$, of superalkali... $\mathrm{CO}_{2}$ complexes obtained from CBS-QB3 calculations; charge transfer, $\Delta q$ (a.u.), from the superalkali to $\mathrm{CO}_{2}$ and electric charge $q$ (a.u.) on each molecule calculated using the ESP method.

\begin{tabular}{|c|c|c|c|c|c|}
\hline species & $\Delta E(\mathrm{~kJ} / \mathrm{mol})$ & $B E^{1}(\mathrm{~kJ} / \mathrm{mol})$ & $\Delta q($ a.u. $)$ & $\mathrm{qCO}_{2}$ & $\mathrm{q}_{\mathrm{Li}} \mathrm{k}_{\mathrm{1}} \mathrm{F}_{\mathrm{k}}$ \\
\hline $\mathrm{Li}_{2} \mathrm{~F} \cdots \mathrm{CO}_{2}$ structure a & 45 & $-118(-115)$ & 0.61 & & \\
\hline $\mathrm{Li}_{2} \mathrm{~F} \cdots \mathrm{CO}_{2}$ structure $\mathrm{b}$ & 0 & $-164(-171)$ & 0.83 & & \\
\hline $\mathrm{Li}_{3} \mathrm{~F}_{2} \cdots \mathrm{CO}_{2}$ structure a & 5 & $-158(-180)$ & 0.76 & & \\
\hline $\mathrm{Li}_{3} \mathrm{~F}_{2} \cdots \mathrm{CO}_{2}$ structure $\mathrm{b}$ & 0 & $-162(-184)$ & 0.62 & & \\
\hline $\mathrm{Li}_{3} \mathrm{~F}_{2} \cdots \mathrm{CO}_{2}$ structure $\mathrm{c}$ & 10 & $-155(-171)$ & 0.79 & & \\
\hline $\mathrm{Li}_{3} \mathrm{~F}_{2}\left(C_{2 \mathrm{v}}\right) \cdots \mathrm{CO}_{2}+$ pyridine & & $-162^{2}$ & & -0.74 & 0.52 \\
\hline $\mathrm{Li}_{4} \mathrm{~F}_{3} \cdots \mathrm{CO}_{2}$ structure a & 53 & $-155(-182)$ & 0.70 & & \\
\hline $\mathrm{Li}_{4} \mathrm{~F}_{3} \cdots \mathrm{CO}_{2}$ structure $\mathrm{b}$ & 50 & $-158(-178)$ & 0.63 & & \\
\hline $\mathrm{Li}_{4} \mathrm{~F}_{3} \cdots \mathrm{CO}_{2}$ structure $\mathrm{c}$ & 40 & $-158(-174)$ & 0.81 & & \\
\hline $\mathrm{Li}_{4} \mathrm{~F}_{3} \cdots \mathrm{CO}_{2}$ structure $\mathrm{d}$ & 0 & $-184(-201)$ & 0.87 & & \\
\hline $\mathrm{Li}_{5} \mathrm{~F}_{4} \cdots \mathrm{CO}_{2}$ structure a & 65 & $-150(-179)$ & 0.69 & & \\
\hline $\mathrm{Li}_{5} \mathrm{~F}_{4} \cdots \mathrm{CO}_{2}$ structure $\mathrm{b}$ & 62 & $-153(-173)$ & 0.62 & & \\
\hline $\mathrm{Li}_{5} \mathrm{~F}_{4} \cdots \mathrm{CO}_{2}$ structure $\mathrm{c}$ & 28 & $-158(-174)$ & 0.81 & & \\
\hline $\mathrm{Li}_{5} \mathrm{~F}_{4} \cdots \mathrm{CO}_{2}$ structure $\mathrm{d}$ & 0 & $-156(-172)$ & 0.79 & & \\
\hline $\mathrm{Li}_{5} \mathrm{~F}_{4}\left(C_{2 \mathrm{v}}\right) \cdots \mathrm{CO}_{2}+$ pyridine & 74 & $-162^{2}$ & & -0.74 & 0.54 \\
\hline $\mathrm{Li}_{5} \mathrm{~F}_{4} \cdots \mathrm{CO}_{2}+$ pyridine & 22 & $-160^{2}$ & & -0.80 & 0.64 \\
\hline $\mathrm{Li}_{5} \mathrm{~F}_{4}\left(C_{3 \mathrm{v}}\right) \cdots \mathrm{CO}_{2}+$ pyridine & 0 & $-154^{2}$ & & -0.75 & 0.65 \\
\hline
\end{tabular}


Table 2: Relative stability, $\Delta E$, between isomers, interaction energy of superalkalis and graphene, $\Delta U(\mathrm{~kJ} / \mathrm{mol})$, and superalkalis and $\mathrm{CO}_{2}, B E(\mathrm{~kJ} / \mathrm{mol})$, obtained from B3LYP/6-31G(d) calculations and electric charge $q$ (a.u.) on each molecule of the complex calculated using the ESP method.

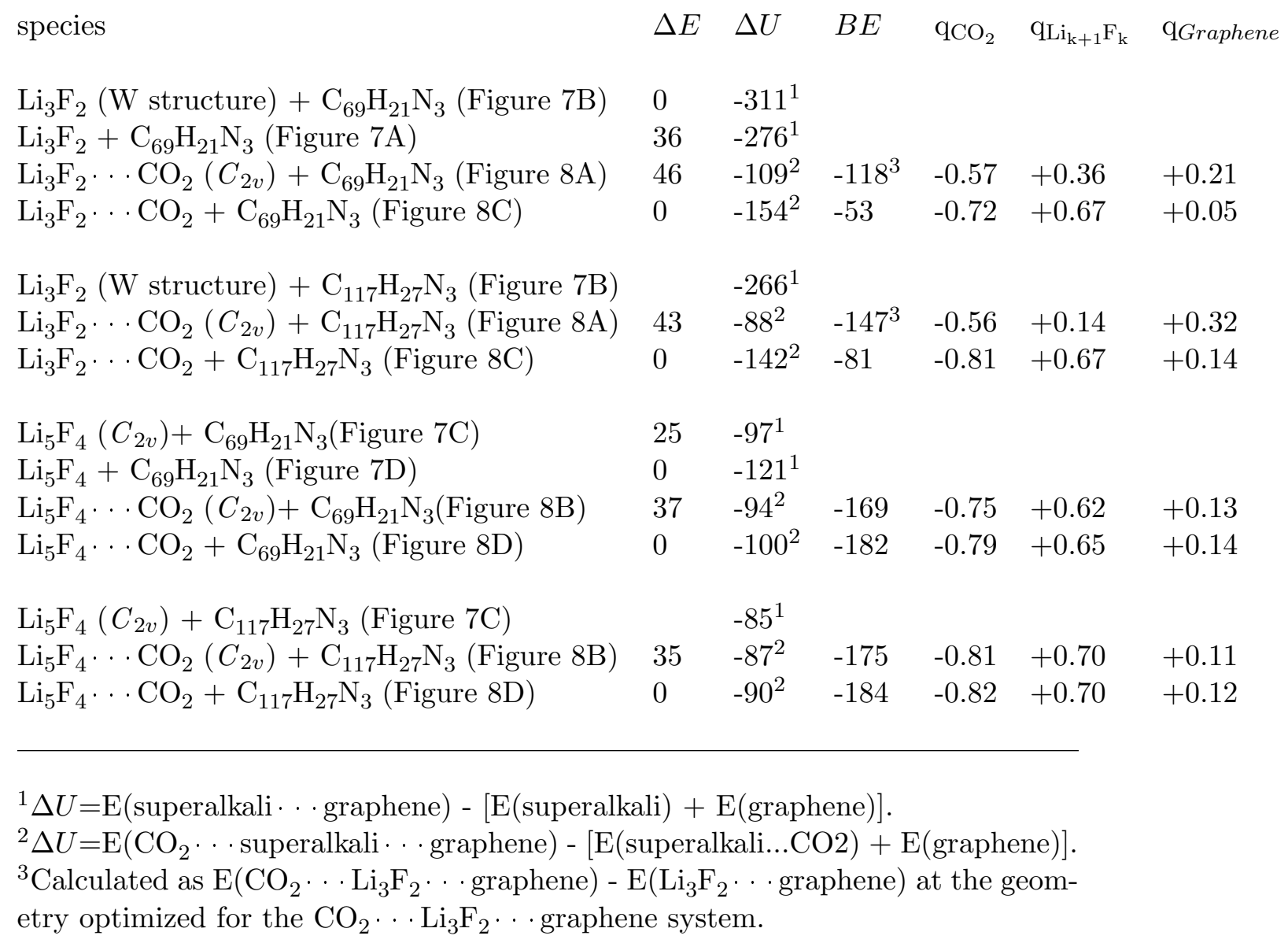

